\title{
The Role of Bridging Cultural Practices in Racially and Socioeconomically Diverse Civic Organizations
}

\author{
Ruth Braunstein \\ University of Connecticut \\ Brad R. Fulton \\ Duke University \\ Richard L. Wood \\ University of New Mexico
}

Corresponding Author: Ruth Braunstein, Department of Sociology, University of Connecticut, Unit 1068, 344 Mansfield Road, Storrs, CT 06269

E-mail: ruth.braunstein@uconn.edu

\begin{abstract}
Organizations can benefit from being internally diverse, but they may also face significant challenges arising from such diversity. Potential benefits include increased organizational innovation, legitimacy, and strategic capacity; challenges include threats to organizational stability, efficacy, and survival. In this article, we analyze the dynamics of internal diversity within a field of politically oriented civic organizations. We find that "bridging cultural practices" serve as a key mechanism through which racially and socioeconomically diverse organizations navigate challenges generated by internal differences. Drawing on data from extended ethnographic fieldwork within one local faith-based community organizing coalition, we describe how particular prayer practices are used to bridge differences within group settings marked by diversity. Furthermore, using data from a national study of all faith-based community organizing coalitions in the United States, we find that a coalition's prayer practices are associated with its objective level of racial and socioeconomic diversity and its subjective perception of challenges arising from such diversity. Our multi-method analysis supports the argument that diverse coalitions use bridging prayer practices to navigate organizational challenges arising from racial and socioeconomic diversity, and we argue that bridging cultural practices may play a similar role within other kinds of diverse organizations.
\end{abstract}

\section{Keywords}

civil society, community organizing, organizational culture, racial and socioeconomic diversity, religion

Although organizations can benefit from internal diversity, they may also confront challenges arising from such diversity. Under the right conditions, internally diverse organizations can benefit from gains in innovation and creativity (Amabile 1996; Jehn, Northcraft, and Neale 1999) and, in politically oriented organizations, increased legitimacy and strategic capacity (Ganz 2000, 2009). Yet internal diversity can also present challenges that threaten organizational stability, efficacy, and survival (Allen 1974; Gawerc 2012; Leondar-Wright 2014; Warren 2001; Williams and O'Reilly 1998). We analyze the dynamics of internal diversity within a field of politically oriented civic organizations: faith-based community organizing (FBCO). ${ }^{1}$ Drawing on 
data from a national study of FBCO coalitions in the United States, and using evidence from extended ethnographic fieldwork within one local coalition, we find that "bridging cultural practices" serve as a key mechanism through which racially and socioeconomically diverse organizations navigate challenges generated by internal differences, and we analyze how these practices function within a diverse coalition.

The FBCO field has characteristics of both social movements and civic organizations. On one hand, FBCO coalitions look much like social movement organizations: they address issues through the public exercise of political power by engaging constituents via mobilizing structures (McAdam, McCarthy, and Zald 1996; McAdam, Tarrow, and Tilly 2001; McCarthy and Zald 1977; Morris 1984; Tarrow 1994). On the other hand, these groups specifically eschew issue mobilization as a goal, in favor of long-term organizing to build enduring structures that can address a broad set of issues. Their (relatively) formalized practices and organizational structures look more like those of civic organizations than like the emergent forms associated with social movements. Moreover, their most common forms of public engagement look more like collective civic actions (Sampson et al. 2005) than social protests. In characterizing the FBCO field, we thus use the term "politically oriented civic organizations" to capture the boundary niche in which it resides.

\section{BENEFITS AND CHALLENGES OF INTERNAL DIVERSITY}

The organizational behavior literature demonstrates that organizations can benefit significantly from internal diversity. Diversity can enhance creativity and innovation within organizations (Amabile 1996), and when properly managed it can improve organizational performance (Jehn et al. 1999). Building a diverse membership is particularly beneficial within politically oriented civic organizations. For example, one study of farm labor organizing indicates that internally diverse groups have more strategic capacity, and thus greater political efficacy (Ganz 2000, 2009 see also Warren 2001). In addition, politically oriented civic organizations that reflect the diversity of the communities they represent possess greater political legitimacy (Chambers 2003; McCarthy 1995; Parekh 2002).

On the other hand, internal diversity can produce significant organizational challengesespecially for politically oriented civic organizations. Diversity can threaten organizational coherence (Ansell, Reckhow, and Kelly 2009; Williams and O'Reilly 1998), undermine social cohesion (Putnam 2007), and increase the risk of co-optation (Kadushin et al. 2005). Furthermore, many social movements fail because their racially homogenous group cultures and norms render them incapable of comprehending and embracing multiracial realities (Allen 1974).

Recent research demonstrates the specific challenges posed by racial and socioeconomic diversity within politically oriented organizations. An analysis of racial diversity within the environmental justice movement shows that the divide between African Americans and Latinos undermines multiracial organizing in Los Angeles, and the destabilization of fixed identities in postmodern culture makes identity work within racially diverse organizations especially difficult (Pulido 1996). In one of the few studies to analyze effects of socioeconomic diversity within organizations, Leondar-Wright (2005) shows how an inability to understand and bridge different class cultures within class-diverse organizations undermines members' capacity to address 
common organizational challenges (for other examples, see Croteau 1995; Stout 1996). ${ }^{2}$ A recent study analyzing multidimensional diversity within organizations finds that high internal diversity along racial, socioeconomic, and religious lines can produce asymmetrical power relations within an organization (Gawerc 2012). The tensions generated by this asymmetry represent a persistent threat to organizational stability - a crucial determinant of long-term social movement success (Gamson 1975).

Although these studies provide insights into the relationship between internal diversity and organizational strength, none focus on organizational efforts to address challenges associated with internal diversity. We now turn to this issue.

\section{DIVERSITY IN FBCO COALITIONS}

In the past decade, the FBCO field has received extensive attention from scholars (see Bretherton 2010; Day, McIntosh, and Storrar 2013; Hart 2001; Osterman 2003; Stout 2010; Swarts 2008; Warren 2001; Wood 2002) and academically inclined practitioners (Chambers and Cowan 2003; Gecan 2009; Jacobsen 2001; Whitman 2007). The typical FBCO coalition brings together roughly two dozen organizational members (mostly religious congregations, but also labor unions, immigrant organizations, neighborhood associations, and others); it then trains leaders from within those organizations to identify and advocate for policies that better serve poor, working-class, and middle-income communities.

In contrast to many civic organizations, which tend to be racially and socioeconomically homogenous (Costa and Kahn 2003; McPherson, Smith-Lovin, and Cook 2001; Skocpol 2002), a large proportion of FBCO coalitions have substantial internal diversity along racial and socioeconomic lines (Fulton and Wood 2012; Wood, Fulton, and Partridge 2012). These coalitions pursue this diversity intentionally, believing they gain political credibility in the public sphere by organizing a base that reflects the diversity of their communities. They do so by creating enduring ties between multiple member organizations, which individually may be relatively homogenous but collectively represent substantial diversity.

For purposes of comparison, over 50 percent of FBCO coalition board members are non-white (Wood, Fulton, and Partridge 2012), whereas only 19 percent of all nonprofit board members in the United States and 13 percent of Fortune 500 board members are non-white (Lang et al. 2011; Ostrower 2007). In terms of socioeconomic diversity, over 50 percent of FBCO coalition board members have a household income of less than $\$ 50,000$ per year, and roughly 25 percent have less than a bachelor's degree (Wood, Fulton, and Partridge 2012). Although no nationally representative data on the socioeconomic status of nonprofit boards exist, the FBCO field clearly incorporates greater socioeconomic diversity than most nonprofit boards. In addition, FBCO coalition board members represent a range of religious traditions, including Catholics (36 percent), Mainline Protestants (29 percent), Black Protestants (19 percent), Conservative Protestants (7 percent), Jews (5 percent), and Muslims (1 percent). ${ }^{3}$

These coalitions endeavor - albeit not always successfully - to forge a common identity across their racial, socioeconomic, and religious differences (Hart 2001; Wood 1999, 2002; Swarts 2008; Warren 2001). Even when done successfully, this identity does not develop spontaneously, 
nor is it stable once established. It requires ongoing effort. As a result, these coalitions offer windows into the practices organizations use to bridge internal differences and build shared group cultures.

While racial and socioeconomic differences can complicate coalitions' efforts to build a shared identity, religious differences do not appear to have the same effect; rather, religion can play a unifying role in this process. ${ }^{4}$ Because these coalitions organize primarily through religious congregations, they draw heavily on religion to build shared group cultures (Wood 1999, 2002; Hart 2001; Stout 2010). For example, Warren (2001:117) shows how religious ties help build trust within multiracial coalitions, and how prayers "act as symbols to remind participants of their religious commonality" despite racial differences. To motivate collective efforts, coalitions focus on one of the few things most participants share: they develop collective identities as people of faith. Of course, faith is not their only commonality; they also share an interest in addressing quality of life issues (like safety, health, and housing) in their community. Yet shared interests do not guarantee cooperation. FBCO coalitions emphasize a shared faith identity as one means of building the shared culture and meanings required to work together toward shared goals. These coalitions thus offer windows into how religious practices can be used in diverse settings to bridge internal differences.

\section{BRIDGING CULTURAL PRACTICES: FORGING GROUP CULTURES ACROSS DIVERSITY}

Social movement scholarship offers insights into how groups forge shared group cultures and identities across differences. A pivotal insight of the cultural turn in social movement research is that collective actors do not simply exist; they are made (Calhoun 1994; see also Bernstein 2005; Polletta and Jasper 2001). Using a constructivist approach to culture and identity, scholars have revealed collective identities less as the products of ascribed categories - like race, gender, or class - and more as markers that are chosen and earned by the people involved (Fantasia 1988; Gamson 1992; Reger, Myers, and Einwohner 2008; Schwalbe and Mason-Schrock 1996). Collective identities are the product of "joint action, negotiation, and interpretive work" (Snow and McAdam 2000:46) and achieved through a variety of cultural practices. Groups may signify and affirm identities by selectively associating with or distancing themselves from certain people, by wearing certain clothing or listening to certain kinds of music, or by engaging in certain activities (Bernstein 2008; Snow and Anderson 1987).

Practices used to construct shared identities across differences constitute a particular kind of identity work, which we call bridging cultural practices. These practices need not produce sameness, but rather organize difference (Ghaziani and Baldassarri 2011). They do so in the following ways: first, by defining a category in which all group members could position themselves; second, by signaling the openness of this category to all group members; third, by enacting rituals or referencing discourses and symbols that are familiar to all group members (or, conversely, learned by all group members together) and thus potentially meaningful to all (even if in different ways); and fourth, by highlighting characteristics that group members share (at least putatively), while either downplaying or celebrating their differences.

Bridging cultural practices are shaped by existing institutional norms and reference familiar 
routines and repertoires, yet they also have the potential to reshape the institutions in which they are enacted. In this regard, they represent precisely the kinds of grounded practices that practice theorists locate at the root of broader social changes (even while they may also reinforce existing systems of difference) (Bourdieu 1977; Ortner 1984).

Bridging cultural practices are neither inherently nor entirely inclusive. Indeed, theories of boundary work underscore the extent to which the construction of any group or category simultaneously involves both inclusion and exclusion (Lamont and Fournier 1992). The doubleedged nature of group building is especially evident in studies of faith-based civic organizations (Bartkowski and Regis 2003; Lichterman 2005; Putnam and Campbell 2010). That said, this research primarily focuses on internally homogenous groups, leading to the expectation that diversity is something groups confront externally, when they interact with other homogenous groups. Moreover, by focusing on religion's tendency to create strong in-group bonds or complicate between-group interactions, this literature largely overlooks the extent to which religion can also offer important cultural resources for bridging internal differences. Studying internally diverse civic organizations - exemplified here by FBCO coalitions - offers an opportunity to fill these gaps in research.

Yet diverse organizations vary in their capacity to incorporate bridging cultural practices. Organizations marked by high levels of institutionalization (e.g., some schools and corporations) have limited space for such practices, while organizations with institutional flexibility and relative autonomy (e.g., some voluntary associations) provide free space in which such practices can arise (Evans and Boyte 1986; Polletta 1999). We thus expect to find bridging practices in organizations where diversity is high and formal institutionalization is relatively low.

By organizing difference rather than producing sameness, these practices resemble Ghaziani and Baldassarri's (2011) cultural anchors. Although they associate this concept with symbols and discourse, we propose that multivalent practices that anchor participants to shared projects (within diverse coalitions or across time), while also allowing participants to recognize and celebrate their differences, perform similar cultural work. In so doing, bridging cultural practices can generate what Gawerc (2012) calls integrative ties, which she argues are crucial for overcoming power differentials and creating stability within diverse organizations.

Yet little is known about how politically oriented civic organizations manage racial and socioeconomic diversity in practice. Studies of other types of diverse organizations - namely, multiracial congregations (Becker 1998; Emerson 2006; Marti 2012) and transnational social movements (Nepstad 2001)—show participants reworking familiar religious practices (like prayer, music, and narrative) in the course of enacting overarching collective identities that recognize, yet transcend, the more particular identities that divide participants. Recent research provides some evidence suggesting that religious practices - and prayer in particular-could also perform this function within racially and socioeconomically diverse civic organizations.

First, Warren (2001) shows how group prayers can unify racially diverse civic organizations; however, he does not assess prayer's role in bridging socioeconomic differences or whether prayer operates similarly beyond his research site. Second, Verba, Schlozman, and Brady (1995) note that individuals across races and socioeconomic statuses participate in religious life at 
similar rates. Although religion is undoubtedly infused with vertical social power of various kinds, it nonetheless provides a common well of practices and norms - including prayer-with which a diverse range of Americans are familiar and comfortable. It would thus seem reasonable for groups to engage in prayer when seeking to build solidarity despite internal differences. Third, Loveland and colleagues (2005) find that private prayer increases civic involvement by heightening sympathy for others. Although not addressed by their study, it is possible that collective prayer could also trigger other-oriented feelings that facilitate group solidarity. Indeed, Wuthnow (2008) highlights the expressive qualities of prayers and how they can promote solidarity and identify group boundaries. Yet, he also notes that insufficient attention has been given to the content and form of these prayers and how they vary across social settings.

In this article, we begin to fill these gaps by investigating the use of prayer as a bridging cultural practice within the FBCO field, paying particular attention to how the form and content of prayers vary across social settings. We are not analyzing private or silent prayers, but prayers, reflections, and related religious practices that are intentionally spoken to other people. Likewise, we are not analyzing individual outcomes associated with prayer (Bradshaw, Ellison, and Flannelly 2008; Ellison and Taylor 1996), but rather the organizational effects of collective prayer practices. Finally, we are not arguing that these practices are used exclusively to bridge differences. Many people we observed leading corporate prayers, for example, would likely insist that their primary interlocutor is God. Still, this does not preclude the possibility that their prayers also function as ways of communicating with other people present (Wuthnow 2008). As Ladd and Spilka (2002:477) argue, prayers can have inward, outward, and upward dimensions, with the outward aspects focused on "strengthening human-human connections." These outward aspects of spoken prayer are our primary interest.

\section{DATA AND METHODS}

We analyze data from two major research projects. The first dataset involves qualitative data collected through two years of ethnographic fieldwork and 29 interviews conducted by the first author in one FBCO coalition. Through detailed analyses of participants' interactions, the qualitative component shows how bridging cultural practices are used to meet the challenges of diversity within one coalition. The second dataset involves quantitative data collected from a national study of FBCO coalitions. The quantitative component shows that the relationship between racial and socioeconomic diversity and the use of bridging cultural practices transcends the one organization studied ethnographically and in fact holds across a full array of organizations within a national field of politically oriented civic organizations.

\section{Qualitative Data}

We draw on data collected through ethnographic fieldwork in one FBCO coalition-Interfaith. ${ }^{5}$ Established in 2008, Interfaith is located in a large Northeastern city and draws participants from 22 member congregations, which represent substantial racial, socioeconomic, and religious diversity (see Table 1 for Interfaith's descriptive statistics). Overall, this composition places Interfaith slightly above the national average of all FBCO coalitions in terms of its religious, racial, and income diversity, and below average in terms of its educational diversity. Like other FBCO coalitions, Interfaith develops participants' capacity to identify problems in their 
communities and hold decision-makers accountable via public actions.

Most of Interfaith's members reside in two neighborhoods: one is predominantly white and middle-class, and the other is racially/ethnically diverse and lower income. Because Interfaith organizes primarily around issues facing individual neighborhoods, much of its activity occurs within small groups of volunteer leaders within congregations or clusters of neighboring congregations and other organizations. Between 2010 and 2012, during the fieldwork period, a group of predominantly white, middle-class leaders in one neighborhood worked on issues related to healthcare affordability and access, while groups of predominantly black (African American and Caribbean), low- and middle-income leaders in another neighborhood worked on issues related to immigration, economic justice, housing, and bank accountability.

During this two-year period, Interfaith also held coalition-wide events that brought together all of its volunteer leaders from both neighborhoods. These events included training sessions, quarterly meetings, the annual general assembly, and some of the organization's larger public actions. During this time, the first author attended the majority of these coalition-wide events and became a regular participant in the local working-group that focused on healthcare. Over the course of fieldwork, she typically volunteered to assist with basic tasks like note taking and setting up before meetings. This position allowed her to blend into the action while offering optimal conditions for close observation.

\section{Quantitative Data}

The National Study of Faith-Based Community Organizing Coalitions is a survey of all coalitions practicing this model of organizing in the United States as of 2011 (for details, see Part A of the online supplement [http://asr.sagepub.com/supplemental]) (Fulton et al. 2011). Although these coalitions are situated in different community contexts, they share a similar organizational form. Each coalition recruits a broad array of community organizations to become dues-paying members. The types of members include religious congregations, neighborhood associations, schools, and unions, with congregations constituting 78 percent of member organizations. Each coalition has a board of directors consisting of representatives from their member organizations. These commonalities mean our analysis holds coalitions' organizational form relatively constant while varying their social composition and organizational activities. The national study surveyed the entire field of these coalitions and achieved a response rate of 94 percent — gathering data on 178 of the 189 coalitions in the country, and demographic information on the 4,145 member organizations and 2,939 board members affiliated with these coalitions. The following sections

use the qualitative and quantitative data to investigate how prayer as a cultural practice is used by FBCO coalitions seeking to bridge racial and socioeconomic differences.

\section{<Table 1 about here $>$}

\section{CASE STUDY: FORGING A SHARED GROUP CULTURE ACROSS RACIAL AND SOCIOECONOMIC DIVIDES}

When Interfaith's participants gather, their interactions help them build shared understandings of their relationships to one another. In this section, we present an in-depth analysis of 29 such 
gatherings, drawing on field notes and transcripts of events and interviews. We are specifically interested in how Interfaith bridges racial and socioeconomic divides within its coalition. As discussed in the previous section, participants gather in different kinds of settings that vary in racial and socioeconomic diversity. Lichterman (2012) argues that group interactionsspecifically religious practices - are likely to vary depending on the nature of the setting in which actors gather (see also Bender 2003). To this end, we divided these gatherings according to whether the setting was racially and socioeconomically diverse $(n=13)$ or homogenous $(n=$ 16) (all settings were religiously diverse). This allows us to assess whether Interfaith's prayer practices differed depending on the racial and socioeconomic diversity of the setting.

Gatherings that brought together leaders from a majority of Interfaith's member congregations and neighborhoods, and exhibited high levels of racial and socioeconomic diversity, are categorized as diverse settings. Racial and socioeconomic diversity can be difficult to disentangle through observation, because race/ethnicity maps closely onto socioeconomic status in these neighborhoods, so we simply note that both are present. The national study (discussed in the next section) is able to isolate each form of diversity more clearly, and thus offers deeper insight into differences between them. These diverse gatherings provided critical opportunities for the coalition to build an overarching group culture that bound participants in a shared project that was larger than the work of any single congregation or neighborhood. These gatherings thus serve as useful windows into the cultural processes through which group members bridge their differences.

Interfaith's leaders also interacted within individual congregations and neighborhood-based working-groups. These gatherings, which exhibited low levels of racial and socioeconomic diversity, are categorized as (relatively) homogenous settings. Meetings of a healthcare workinggroup, in which the first author was a regular participant, serve as examples of such a setting. For 18 months, 10 to 15 core members of this working-group met one to two times per month. This working-group included leaders from local Catholic, Lutheran (Evangelical Lutheran Church in America, and Jewish congregations and a local faith-based hospital. Although participants were religiously diverse, the large majority (including the first author) were white, middle-class professionals. ${ }^{6}$ The term "homogenous" here indicates that these settings were substantially less racially and socioeconomically diverse than others, not that they were absolutely homogenous.

\section{Prayer as a Bridging Cultural Practice in Diverse Settings}

In diverse settings, Interfaith's clergy regularly led collective religious practices - most commonly spoken prayers or embodied prayer practices, but occasionally other kinds of religious talk or embodied rituals — that directed participants' attention to their shared identity as people of faith and the shared convictions that mobilized them to participate in Interfaith. Because these practices typically took place during a time set aside for prayer or reflection, we refer to them as prayers, even though they incorporated religious practices extending well beyond traditional prayers found in most places of worship.

Among the diverse gatherings observed, all but one included some kind of prayer, and more than half included multiple prayers offered by clergy representing different faith traditions and often delivered in different languages - most commonly English and Spanish, but also occasionally 
Creole, Russian, Hebrew, or Arabic. Inviting multiple clergy to pray demonstrated the organization's inclusivity and pulled diverse participants beyond their differences into a partially shared identity as members of this diverse faith community.

Bridging efforts at diverse events were not limited to arranging for multiple and accessible prayers. The content and form of the prayers also performed bridging work. Specifically, we observed two kinds of prayer content and two prayer forms that were used to emphasize the qualities that Interfaith's members share as people of faith, while downplaying or celebrating their differences. These prayers were also used to underscore the potential inclusivity of this identity category to all participants, regardless of their religion, race, ethnicity, or class. At times, these contents and forms occurred in combination, illustrating that a single prayer could perform bridging work on multiple levels.

\section{Bridging through Prayer Content: Offering Interfaith and Prefigurative Prayers}

First, clergy offered interfaith prayers - prayers attempting to be inclusive of every faith tradition present. Interfaith prayers were the most common bridging practice observed, and were present in over three-quarters of diverse gatherings analyzed. These prayers bridge religious differences, but they are also crucial for bridging racial and socioeconomic differences, because achieving racial and socioeconomic diversity in these groups often requires organizing across different religious communities. When Haitians from a Catholic church, Arab Americans from a Muslim organization, and Latinos from a Lutheran congregation work together to address issues facing immigrants in their community, or when low-income and middle-class coalition partners from different congregations work together to demand affordable community healthcare, one of the few things they all share is that they are all people of faith. By abstracting away from their specific religious affiliations, the fact that they are all people of faith becomes a source of commonality rather than division. In these contexts, interfaith prayers emphasize this shared identity, binding participants together across their other differences.

Some clergy transformed prayers drawn from their own traditions into interfaith prayers by instructing audience members to direct prayers to their respective understandings of God. For example, during Interfaith's General Assembly, an annual event that brings the entire coalition together, an Italian American Catholic priest called everyone to prayer: "If you are Jewish, stand for Adonai. If you are Muslim, stand for Allah. If you are Christian like me, stand for Jesus" (event transcript).

Others offered prayers from their own traditions, but replaced any references to a single faith tradition with "neutral" terminology. For example, toward the end of a daylong clergy-lay leader retreat, a Catholic priest reported that he had been asked to do "the impossible," to offer "a Christian prayer that Jews and . . Muslims can do." He constructed a prayer exercise based on the Vespers, a Christian evening prayer. He joked that he did not know if he would be punished for it, but he had removed all of the explicitly Christian parts so that everyone could participate.

Finally, some avoided prayers drawn from any religious tradition by incorporating nonreligious texts-like news articles, poetry, and social criticism — into their reflections. During a training session to address the challenges of racial injustice in their work and in society at large, a white 
male Lutheran pastor drew on the writing of W.E.B. Du Bois and Wendell Berry:

For me, I needed to always turn to some sources of wisdom during this time. . . . And I went back to read W.E.B. Du Bois, some of his language, his words, because he said at the very turn of the last century very similar things that we are thinking and feeling and understanding today. So I'm gonna read just some snippets of his, what's called "credo," written in 1918. Snippets of credo. "I believe in God," he says, "who made of one blood all nations that on earth do dwell. I believe that all men," he said, "black and brown and white are brothers, varying through time in opportunity, in form, in gift, in feature, but differing in no essential particular, and alike in soul, and the possibility of infinite development." ... We are people seeking to make the world better and to align ourselves with many other voices, which is the beauty of what's happening around our country. People are speaking again, and not recognizing each other's differences. That is power. ... In my language, when we're done with meditation, we always say, "So be it. Amen." (event transcript)

It is possible that citing intellectuals like Du Bois and Berry reaffirms educational differences between this pastor and his audience. However, by quoting these authors at length, the pastor endeavors to bring the group into collective reflection on these texts.

In each of these cases, prayers were structured to appeal to different faith traditions and, by extension, to people of different racial and socioeconomic backgrounds. The first example of interfaith prayer sought to bridge differences by being as inclusive as possible. The second example rested on the (perhaps flawed) assumption that common ground could be found in the semblance of neutrality. The third example sought to bridge differences by transcending them.

A second way prayer content performed bridging work was through prefigurative prayers, in which clergy outlined their vision of what a diverse and healthy democracy should look like, and the ways their work together prefigured that vision. Prefigurative prayers were observed in nearly two-thirds of the diverse gatherings analyzed. For example, when the Lutheran pastor drew on the words of Du Bois to create an interfaith prayer, he also quoted Du Bois to communicate his vision of an alternative future society in which "all men, black and brown and white, are brothers." He then connected this vision to Interfaith's work, noting, "We are people seeking to make the world better and to align ourselves with many other voices." By defining the group's work in these terms, he highlighted their goals of cultivating internal and external relationships marked by an appreciation for diversity.

\section{Bridging through Prayer Form: Enacting Relationships and Sharing Prayer Practices}

Prayers also took two forms that performed bridging cultural work. Although these prayer forms were observed less often than interfaith and prefigurative prayers, they produced the most tangible displays of bridging cultural practices at work. First, in about two-fifths of the diverse gatherings observed, clergy encouraged coalition members to physically interact with each other during collective prayers. Some of these rituals resembled those found in other religious settings: people were asked to shake hands, hug their neighbor, or join hands in a circle. But other rituals were tailored to the specific bridging needs of the group. For example, when a Rabbi from a progressive synagogue led the opening reflection at a training session focused on building 
relationships, she spoke of the challenges faced by the Jews after they were sent to wander the desert. Before offering her prayer, she recounted how the Jews built relationships as free members of a new society:

One of the things that really strikes me about this journey is the instructions for the priests, who are the leaders . . . responsible for carrying the communal center - the Tabernaclethrough the desert. So when the priests are being prepared for their role, they put oil—do this with me [she acts out putting oil on her ear and encourages others to follow along] - they put oil on their ear. Yeah, put it on. And on their thumb. And on the toe, the big toe of their foot. [Everyone laughs as she lifts up her foot and touches her toe.]

It's an amazing set of reminders for us, too, as we gather in relationship building. Because it meant that these leaders - and all of us are leaders tonight - had to listen well first. The first thing was the ear. ... Second, they had to reach out their hand — right? - to connect to someone, and to use that human connection. What makes us human? It's our thumbs. ... And then to make those connections, they couldn't just stand there and reach out their hand. They had to walk over and connect with somebody — right? — which made an active possibility of connection all over the six hundred thousand and more people... .

Let's turn our attention to prayer for a minute, and be thinking about your ear, and your thumb, and your toe. Let's turn to God. We ask you, oh God, who creates human beings in your image, and teaches us the way to walk through our life, that you give us knowledge, knowledge that we need to go back to our communities to create relationships, to organize there, so that eventually we can reach out into our entire city and improve the lives of so many. And in that way, we'll be listening, and we'll be reaching out, and we'll be taking the steps to make that happen. Amen. (event transcript)

By engaging participants' bodies in collective rituals surrounding spoken prayer or encouraging transgressions of personal space, practices like these draw the group together into shared embodied experiences. These rituals create opportunities for individuals to enact the relationships they seek to create or strengthen.

Second, in approximately one-quarter of the diverse gatherings observed, leaders from minority faiths shared their communities' prayer practices, using these moments as opportunities to educate Protestants and Catholics regarding Jewish, Muslim, and other less familiar prayer practices. For example, during the opening reflection of a clergy-lay leader retreat, the leader of an Arab American organization demonstrated how Muslims pray. Interfaith's executive director suggested that everyone stand up and join him if they wanted to and felt comfortable. Around 30 people - everyone present - stood. A few black Haitian women in their 60s, from a Catholic parish, stood near two Catholic priests and a Dutch Reformed minister, all older white men. An unemployed woman from a lower-income neighborhood stood alongside middle-class professionals. An interracial couple in their early 40s, white women of various ages and religions, and a handful of other clergy were also scattered around the tables.

Mirroring the Muslim leader's movements, everyone lifted their hands six inches away from their face, with their palms facing inward, and pivoted their wrists back and forth as if they were brushing away stale air. The Muslim leader explained that this signified clearing their minds and focusing on the act of prayer. Then he told them to slowly bring their hands down toward their 
waist and place one arm across their stomach and the other arm over that one. He explained that this is how he "faces God," once his mind has been cleared, and then he would recite from memory a verse from the Qur'an. Everyone stood with their arms wrapped around their waists, then bowed and recited after him. He then lowered all the way to the ground and, laughing, said that everyone did not need to do this part. He placed his forehead on the floor, and coming back up, he explained this was the closest one could come to God. As he led the demonstration, he alternated between referring to God and Allah, and everybody followed along.

Sharing prayer practices played a key role in bridging religious differences within the group by deepening understanding, building trust, and demonstrating respect. This also facilitated the bridging of racial and socioeconomic divisions in more subtle ways. Whether participants were black or white, Haitian or Italian American, middle-class or low-income, these activities became opportunities for everyone to enact their shared commitment to being open-minded people who seek to build relationships with people who differ from themselves. These practices thus help to reinforce an important dimension of their shared identity as participants in building this diverse community.

\section{Prayer across Different Settings}

The prayer practices observed in diverse settings differed systematically in both content and form from those observed in homogenous settings. The differences, however, might have been driven by the fact that the diverse gatherings were also more public than the homogenous gatherings, and thus may have necessitated more formal and elaborate prayer performances. To address this possible explanation, we further divided the events into public versus internal gatherings. In settings that were public but not diverse, leaders offered prayers, but not the kind of bridging prayers depicted earlier. Conversely, in settings that were diverse but not public, leaders almost always engaged in religious rituals that involved bridging practices (for the full ethnographic analysis, see Part B of the online supplement). Taken together, these findings suggest that as the setting became more racially and socioeconomically diverse, specific kinds of religious practices were used — consciously or not— to bridge these differences.

\section{NATIONAL STUDY: PRAYER PRACTICES AND DIVERSITY IN NATIONAL PERSPECTIVE}

How widespread are the bridging cultural practices we identified within Interfaith? Although the inner life of this coalition is likely shaped by its specific location, its participants' unique qualities, and its particular religious, racial, and socioeconomic composition, it shares much in common with other FBCO coalitions around the country, which use similar organizing models and pursue similar goals. We thus ask whether there is a similar relationship between collective religious practices and racial and socioeconomic diversity in the broader set of coalitions. To answer this question, we use data from the National Study of Faith-Based Community Organizing Coalitions (Fulton et al. 2011) to analyze whether a coalition's prayer practices are associated with its objective level of racial and socioeconomic diversity and its subjective perception of internal challenges arising from such diversity. 


\section{Measures of Prayer, Diversity, and Bridging Challenges}

In the national study, directors were asked how often their coalition incorporates prayer into its activities (e.g., to open or close a meeting). They were also asked if their coalition specifically sponsors prayer vigils - a term commonly used in the field to denote events focused specifically on collective prayer. Although over 95 percent indicated incorporating at least some prayer into their activities, only 60 percent indicated specifically having prayer vigils.

We measure coalitions' social composition by tabulating the race, religious affiliation, household income level, and education level of their board members. To calculate racial diversity of a coalition's board, we use the Blau Index, which takes into account both the number of racial groups and the proportion of each group represented on the board. We also use the Blau Index to calculate religious diversity of a coalition's board. To calculate income and educational diversity of a coalition's board, we use the standard deviation of board members' income and education levels.

While the aforementioned variables measure a coalition's objective level of diversity, the following variables measure its subjective perception of experiencing challenges associated with internal diversity. We assess the extent to which coalitions faced challenges bridging racial differences by measuring how racial differences affected their organizational activities and interactions. Directors were asked to indicate the extent to which racial differences complicated and prolonged their planning meetings over the past 12 months. For both items, we converted the five response options (not at all, minimally, a little, somewhat, and a lot) to a Likert-type scale ranging from 1 to 5. Directors were asked identical questions related to socioeconomic differences; we use these variables to measure the extent to which coalitions perceived challenges in bridging socioeconomic differences.

The analysis also controls for a coalition's geographic region, the director's gender and age, the proportion of board members who are clergy, whether the coalition has any Muslim board members, and the coalition director's religiosity, which is an index based on the frequency with which the director prays privately, reads sacred texts, and attends religious services. Table 1 displays descriptive statistics for the variables used in the quantitative analysis.

\section{Racial and Socioeconomic Diversity Associated with Having Prayer Vigils}

The first analysis examines the relationship between a coalition's objective level of racial and socioeconomic diversity and having prayer vigils. Because the dependent variable-prayer vigils - is dichotomous, we perform logistic regressions and estimate the coefficients using maximum likelihood methods. Table 2 displays the change in the log odds of having a prayer vigil associated with a one standard deviation change in the independent variable (Menard 2011).

\section{$<$ Table 2 about here $>$}

Model 1, which is the base model, regresses on the organizational characteristics and religion variables. It indicates that religiosity of the coalition director and religious diversity of the board are positively associated with having prayer vigils. On the other hand, being located in the South, 
director's age, and having at least one Muslim board member are negatively associated with having prayer vigils. The model also indicates that neither the proportion of board members who are clergy nor the director's gender is associated with having prayer vigils.

Model 2 adds racial diversity of the coalition's board to the base model and controls for the proportion of board members who are black. It indicates that racially diverse coalitions are more likely to have prayer vigils. This finding supports our claim based on ethnographic evidence that racially diverse coalitions use prayer as one response to the challenges associated with bridging racial differences. A potential objection to this interpretation would be that this positive relationship arises spuriously because more diverse coalitions are likely to have a greater proportion of black clergy or lay leaders on their board, and given black churches' historic practice of using public prayer to address political issues, one would expect prayer vigils to be more common among these coalitions (Lincoln and Mamiya 2001; Pattillo-McCoy 1998). However, our model accounts for this objection: even when controlling for the proportion of clergy and black board members, racial diversity remains positively associated with having prayer vigils.

Model 3 adds income diversity of the coalition's board to the base model and controls for the proportion of board members who earn less than $\$ 50,000$ per year. It indicates that coalitions with a broad range of income levels represented on their board are more likely to hold prayer vigils, and thus supports our ethnographically based argument that prayer is used to bridge differences arising from socioeconomic diversity. A possible objection to this interpretation would be that most boards become more economically diverse by increasing the proportion of lower-income board members, and given that people with lower income levels tend to pray more often, this positive relationship with having prayer vigils could be solely the result of economically diverse boards having a greater proportion of low-income members (Baker 2008). However, our model accounts for this objection: even when controlling for the proportion of board members who earn less than $\$ 50,000$ per year, income diversity remains positively associated with having prayer vigils.

Model 4 adds educational diversity of a coalition's board to the base model and controls for the proportion of board members who have less than a bachelor's degree. Contrary to our hypothesis, it indicates that educational diversity of a coalition's board is not significantly related to having prayer vigils. Most boards achieve educational diversity by increasing the proportion of less educated board members, and people with lower levels of education pray more often (Norris and Inglehart 2011). This finding could thus be the result of educational diversity and education level being related to each other and to the likelihood of praying.

Model 5 contains all the variables and demonstrates the stability of the estimations from the previous models. The only differences are that religious diversity becomes insignificant when the racial diversity variable is added, and having at least one Muslim board member becomes insignificant when the socioeconomic diversity variables are added. ${ }^{7}$ Although this analysis does not provide evidence of a relationship between educational diversity and prayer vigils, it does provide strong evidence that a coalition's objective levels of racial and income diversity are positively related to its likelihood of having prayer vigils. The magnitude of their effects is substantial and stable. Each standard deviation increase in racial diversity and income diversity 
of a coalition's board is associated with a 15 and 17 percent increase, respectively, in the odds of the coalition using prayer vigils as an organizing strategy.

This analysis provides substantial support for our argument based on ethnographic evidence: racially and socioeconomically diverse coalitions are more likely to incorporate bridging prayer practices into their activities. It also further specifies that the effect of socioeconomic diversity is primarily driven by income diversity.

\section{Bridging Challenges Associated with Having Prayer Vigils}

Having observed a relationship between a coalition's objective level of racial and socioeconomic diversity and having prayer vigils, the second analysis examines the relationship between a coalition's subjective perception of experiencing challenges bridging racial and socioeconomic differences and having prayer vigils. The models for this analysis include all of the variables from the final model in Table 2 and regress the dependent variable_prayer vigils - on each variable, indicating the extent to which a coalition faced challenges bridging racial or socioeconomic differences. Table 3 displays the fully standardized coefficients from the logistic regressions.

\section{$<$ Table 3 about here $>$}

Models 1 and 2 indicate a positive relationship between a coalition facing racial bridging challenges and having prayer vigils, meaning that coalitions reporting that racial differences complicate and prolong their planning meetings are more likely to have prayer vigils. Models 3 and 4 indicate a positive relationship between a coalition facing socioeconomic bridging challenges and having prayer vigils, meaning that coalitions reporting that socioeconomic differences complicate and prolong their planning meetings are more likely to have prayer vigils. Figure 1 illustrates the magnitude of these relationships by showing the predicted probabilities of a coalition having prayer vigils conditioned on the extent to which it faces a particular bridging challenge. A coalition reporting that racial differences affect their planning meetings "a lot" compared with "not at all" is twice as likely to have prayer vigils, and a coalition reporting that socioeconomic differences affect their planning meetings "a lot" compared with "not at all" is three times as likely to have prayer vigils. Overall, the quantitative analysis demonstrates the generalizability of our ethnographic findings, and also parses out differences between the effects of racial and socioeconomic diversity. It provides strong evidence that a coalition's likelihood of having prayers vigils is associated with its objective levels of racial and income diversity, as well as with its subjective perception of experiencing challenges stemming from internal differences.

\section{<Figure 1 about here>}

\section{CONCLUSIONS}

Previous research has identified a dilemma posed by racial and socioeconomic diversity within politically oriented civic organizations: while diversity can be a means to developing organizational strength and power, it can also complicate the task of building a unifying group culture. In this article, we posit "bridging cultural practices" as a mechanism through which 
organizations address these challenges, and we employ a multi-method approach to investigate the use of collective religious practices - most notably prayer - as bridging cultural practices within diverse FBCO coalitions.

Our ethnographic findings showed that the content and form of prayers differed significantly depending on whether the setting was diverse or homogenous. Because all the settings analyzed were religiously diverse, we could effectively hold religious diversity constant, and thus rule out the possibility that prayer practices employed in diverse settings were used primarily to bridge religious differences. Therefore, we argue that prayer practices employed in diverse settings were used to bridge racial and socioeconomic differences.

Our quantitative analysis then established a more general relationship between a coalition's prayer practices, its level of diversity, and indicators of internal bridging challenges arising from such diversity. Data from the national study support our ethnographic finding that diverse coalitions use bridging prayer practices as a response to the internal challenges associated with racial and socioeconomic diversity.

Although the quantitative analysis cannot be used to determine the causal order of the relationship between diversity, bridging challenges, and prayer practices, the qualitative comparison across settings suggests that, consciously or not, leaders modify their prayer practices when faced with existing or potential challenges arising from internal diversity. That said, we cannot rule out the possibility that such practices may also attract a more diverse membership to a coalition.

Overall, this study underscores the value of multi-method research. Dynamics revealed ethnographically could only be confirmed as broad patterns via quantitative analysis; and further ethnographic analysis illuminated dynamics underlying those patterns. The case study also offered insights not visible in the national data - particularly that the nature of prayers differed across settings. Although prayer was observed in the more racially and socioeconomically homogenous settings, it rarely involved the bridging practices we observed in the diverse settings. This finding suggests, in keeping with much recent work in the sociology of culture (Eliasoph 1996; Lamont 2000; Lamont and Fournier 1992; Lichterman 2005), that attention must be paid not only to the presence of cultural practices, but also to the content and form of practices within specific settings.

The study also contributes to a growing literature on how individuals and groups creatively deploy religion - including practices like prayer - to accomplish interactional goals (Avishai 2008; Sharp 2012). To date, most research on the social contours of prayer has been limited to personal prayer and its effects on mental health and well-being (Bradshaw et al. 2008; Ellison and Taylor 1996). Our study broadens this area of inquiry by offering a detailed portrait of collective prayer in action, and demonstrating its effects on group culture and civic life. The multivalent quality of these prayer practices and the creative ways actors use them to achieve practical goals suggests their relevance extends well beyond the study of religion, to ongoing conversations about the cultural challenges of organizing differences (Ghaziani and Baldassarri 2011). As practice theorists note, although grounded practices like these can reinforce existing divisions between groups, they also have the capacity to generate new social relationships and structures (Bourdieu 1977; Ortner 1984). 
This article thus sharpens our understanding of how diverse organizations address challenges arising from social differences. Yet we would not necessarily expect to find bridging cultural practices in all diverse organizations; they are most likely to occur in diverse organizations that are institutionally flexible. Furthermore, the forms bridging practices take likely differ across organizational fields. For example, while the religious practices we analyzed resonate for the participants in this field, we would not expect bridging cultural practices to take this form within more conservative religious organizations where some participants may not be comfortable with interfaith religious practices, or within secular organizations where prayer may not be considered appropriate or unifying. In such organizations, bridging cultural practices might include sharing meals, making music, or reading literature together. These activities, like the prayer practices we analyzed, emphasize enacting shared identities through collective practices that are meaningful for diverse participants.

Finally, this study has broader implications for the study of civic life. A large body of research suggests that civic life has the capacity to "thicken the ties that bind society" (Lichterman 2005:7) by encouraging citizens to work together - often across great social distances - to solve shared problems facing their communities (Tocqueville 1969; Wuthnow 2002). Our understanding of how this works, however, has been built primarily on studies of internally homogenous groups, which has reinforced two overly narrow generalizations: first, that bonding happens only within homogenous groups, whereas bridging happens only between groups; second, that religion is more likely to create strong in-group bonds and fuel inter-group divisions than help groups bridge internal differences. This study troubles both of these assumptions.

First, we find that religious practices can help bridge differences within diverse organizations. This is not to deny that these practices may also result in certain forms of exclusion. Indeed, a group's use of interfaith prayer practices tacitly limits participants to those who are comfortable with such practices. This could partially explain why theologically conservative congregations do not typically participate in these kinds of groups. Still, by demonstrating how religious practices perform this complex cultural work, we contribute to an ongoing effort to rethink the role of religion in civic life (Braunstein 2012; Lichterman and Potts 2009; Stout 2010; Wood 1999, 2002).

Second, our analysis reveals how bridging and bonding are intertwined, by showing how diverse organizations bridge differences by creating shared identities through practices that simultaneously highlight similarities and either downplay or celebrate differences. This will not be surprising to social movement scholars, who recognize that most movements struggle internally to forge shared identities. Yet many of these insights have not been fully incorporated into debates over the challenges of diversity in civil society.

We begin to do so by demonstrating how politically oriented civic organizations use bridging cultural practices to forge shared cultures across internal differences. If unlocking the benefits associated with organizational diversity requires successfully navigating the challenges arising from social differences, then understanding how organizations use these kinds of practices is critical and merits ongoing scholarly attention.

\section{Acknowledgments}


The authors contributed equally to this article. We would like to thank the ASR editors and anonymous reviewers, as well as Courtney Bender, Jeffrey Guhin, Mala Htun, Kendra Koivu, Mark Peceny, William Stanley, and audience members at the meetings of the Society for the Scientific Study of Religion and the American Sociological Association for their comments on earlier versions of this article.

\title{
Funding
}

We gratefully acknowledge primary funding for the national study provided by Interfaith Funders, along with secondary grants from the Hearst Foundation, Society for the Scientific Study of Religion, Religious Research Association, the Louisville Institute, and Duke University.

\section{Notes}

1. Nomenclature in the field varies; in addition to "faith-based" community organizing, the terms "broad-based," "congregation-based," and "institution-based" refer to similar organizing models sharing historical and institutional roots.

2. These groups also exhibit significant racial/ethnic diversity. Although U.S. demographics render it difficult to disentangle complications arising from class versus racial/ethnic diversity, Leondar-Wright's (2014) focus on class reflects her assessment that class diversity has been overlooked.

3. Although the percentages of Jewish and Muslim board members appear small, their representation is substantial given that Jews and Muslims represent approximately 1.5 percent and 1.1 percent of the U.S. population, respectively (based on the 2012 General Social Survey).

4. The minimal negative impact of religious differences on coalitions' solidarity may be partially due to self-selection: individuals and religious congregations that are uncomfortable with religious diversity (and thus most likely to generate interreligious conflict within the coalition) may leave or opt not to join interfaith coalitions.

5. "Interfaith" is a pseudonym.

6. Among the few non-white participants, most either lived in the neighborhood and shared class characteristics with the others, or worked in the healthcare industry and shared the professional status of the others.

7. Although the initial models indicate that religious diversity is significantly associated with having prayer vigils, the relationship becomes insignificant in the full model (Model 5). This suggests that the effect of religious diversity is mediated by racial and socioeconomic diversity.

\section{References}

<AUTHOR: Please make sure references include authors' middle initials and articles' subtitles, where appropriate. Also, please include issue numbers for all journal articles.>

\author{
Allen, Robert L. 1974. Reluctant Reformers: Racism and Social Reform Movements in the \\ United States. Washington, DC: Howard University Press.
}


Amabile, Theresa M. 1996. "Creativity and Innovation in Organizations." Pp. 123-67 in Research in Organizational Behavior, edited by B. M. Staw and L. L. Cummings. Greenwich, CT: JAI Press.

Ansell, Chris, Sarah Reckhow, and Andrew Kelly. 2009. "How to Reform a Reform Coalition: Outreach, Agenda Expansion, and Brokerage in Urban School Reform." Policy Studies Journal 37(4):717-43.

Avishai, Orit. 2008. “'Doing Religion' in a Secular World: Women in Conservative Religions and the Question of Agency." Gender \& Society 22(4):409-33.

Baker, Joseph O. 2008. “An Investigation of the Sociological Patterns of Prayer Frequency and Content." Sociology of Religion 69(2):169-85.

Bartkowski, John P. and Helen A. Regis. 2003. Charitable Choices: Religion, Race, and Poverty in the Post-Welfare Era. New York: New York University Press.

Becker, Penny Edgell. 1998. 'Making Inclusive Communities: Congregations and the 'Problem' of Race.” Social Problems 45(4):451-72.

Bender, Courtney. 2003. Heaven's Kitchen: Living Religion at God's Love We Deliver. Chicago: University of Chicago Press.

Bernstein, Mary. 2005. “Identity Politics.” Annual Review of Sociology 31:47-74.

Bernstein, Mary. 2008. "The Analytic Dimensions of Identity: A Political Identity Framework." Pp. 277-301 in Identity Work in Social Movements, edited by J. Reger, D. J. Myers, and R. L. Einwohner. Minneapolis: University of Minnesota Press.

Bourdieu, Pierre. 1977. Outline of a Theory of Practice. Translated by R. Nice. Cambridge, UK; New York: Cambridge University Press.

Bradshaw, Matt, Christopher G. Ellison, and Kevin J. Flannelly. 2008. "Prayer, God Imagery, and Symptoms of Psychopathology." Journal for the Scientific Study of Religion 47(4):644-59.

Braunstein, Ruth. 2012. "Storytelling in Liberal Religious Advocacy." Journal for the Scientific Study of Religion 51(1):110-127.

Bretherton, Luke. 2010. Christianity and Contemporary Politics: The Conditions and Possibilities of Faithful Witness. Chichester, West Sussex, U.K.: Wiley-Blackwell.

Calhoun, Craig. 1994. Social Theory and the Politics of Identity. Oxford, UK; Cambridge, MA: Blackwell.

Chambers, Edward T. and Michael A. Cowan. 2003. Roots for Radicals: Organizing for Power, 
Action, and Justice. New York: Continuum.

Chambers, Simone. 2003. "Deliberative Democratic Theory." Annual Review of Political Science 6(1):307-26.

Costa, Dora L. and Matthew E. Kahn. 2003. "Civic Engagement and Community Heterogeneity: An Economist's Perspective." Perspective on Politics 1(1):103-11.

Croteau, David. 1995. Politics and the Class Divide: Working People and the Middle-Class Left. Philadelphia: Temple University Press.

Day, Katie, Esther McIntosh, and William Storrar. 2013. Yours the Power: Faith-Based Organizing in the USA. Leiden: Brill.

Eliasoph, Nina. 1996. "Making a Fragile Public: A Talk-Centered Study of Citizenship and Power." Sociological Theory 14(3):262-89.

Ellison, Christopher G. and Robert J. Taylor. 1996. "Turning to Prayer: Social and Situational Antecedents of Religious Coping among African Americans." Review of Religious Research 38(2):111-31.

Emerson, Michael O. 2006. People of the Dream: Multiracial Congregations in the United States. Princeton: Princeton University Press.

Evans, Sara M. and Harry C. Boyte. 1986. Free Spaces: The Sources of Democratic Change in America. New York: Harper \& Row.

Fantasia, Rick. 1988. Cultures of Solidarity: Consciousness, Action, and Contemporary American Workers. Berkeley: University of California Press.

Fulton, Brad R., Richard L. Wood, and Interfaith Funders. 2011. National Study of Faith-Based Community Organizing Coalitions: Data file. Durham, NC: Duke University, Department of Sociology.

Fulton, Brad R. and Richard L. Wood. 2012. "Interfaith Community Organizing: Emerging Theological and Organizational Challenges." International Journal of Public Theology 6(4): 398-420.

Gamson, William A. 1975. The Strategy of Social Protest. Homewood, IL. Dorsey Press.

Gamson, William A. 1992. Talking Politics. New York: Cambridge University Press.

Ganz, Marshall. 2000. "Resources and Resourcefulness: Strategic Capacity in the Unionization of California Agriculture, 1959-1966.” American Journal of Sociology 105(4):1003-63.

Ganz, Marshall. 2009. Why David Sometimes Wins: Leadership, Organization, and Strategy in 
the California Farm Worker Movement. New York: Oxford University Press.

Gawerc, Michelle I. 2012. Prefiguring Peace: Israeli-Palestinian Peacebuilding Partnerships. Lanham: Lexington Books.

Gecan, Michael. 2009. After America's Midlife Crisis. Cambridge, MA: MIT Press.

Ghaziani, Amin and Delia Baldassarri. 2011. "Cultural Anchors and the Organization of Differences: A Multi-method Analysis of LGBT Marches on Washington." American Sociological Review 76(2):179-206.

Hart, Stephen. 2001. Cultural Dilemmas of Progressive Politics: Styles of Engagement among Grassroots Activists. Chicago: University of Chicago Press.

Jacobsen, Dennis A. 2001. Doing Justice: Congregations and Community Organizing. Minneapolis: Fortress Press.

Jehn, Karen A., Gregory B. Northcraft, and Margaret A. Neale. 1999. "Why Differences Make a Difference: A Field Study of Diversity, Conflict, and Performance in Workgroups." Administrative Science Quarterly 44(4):741-63.

Kadushin, Charles, Matthew Lindholm, Dan Ryan, Archie Brodsky, and Leonard Saxe. 2005. "Why It Is So Difficult to Form Effective Community Coalitions." City and Community $4(3): 255-75$.

Ladd, Kevin L. and Bernard Spilka. 2002. "Inward, Outward, and Upward: Cognitive Aspects of Prayer." Journal for the Scientific Study of Religion 41(3):475-84.

Lamont, Michèle. 2000. The Dignity of Working Men: Morality and the Boundaries of Race, Class, and Immigration. New York: Russell Sage Foundation; Cambridge, MA: Harvard University Press.

Lamont, Michèle and Marcel Fournier. 1992. Cultivating Differences: Symbolic Boundaries and the Making of Inequality. Chicago: University of Chicago Press.

Lang, Ilene, Arnold W. Donald, Carlos F. Orta, and J. D. Hokoyama. 2011. Missing Pieces: Women and Minorities on Fortune 500 Boards. New York: Catalyst.

Leondar-Wright, Betsy. 2005. Class Matters: Cross-Class Alliance Building for Middle-Class Activists. Gabriola Island, BC, Canada: New Society Publishers.

Leondar-Wright, Betsy. 2014. Missing Class: How Seeing Class Cultures Can Strengthen Social Movement Groups. Ithaca, NY: Cornell University Press.

Lichterman, Paul. 2005. Elusive Togetherness: Church Groups Trying to Bridge America's Divisions. Princeton: Princeton University Press. 
Lichterman, Paul. 2012. "Religion in Public Action: From Actors to Settings." Sociological Theory 30(1):15-36.

Lichterman, Paul and C. Brady Potts. 2009. The Civic Life of American Religion. Stanford: Stanford University Press.

Lincoln, C. Eric and Lawrence H. Mamiya. 2001. The Black Church in the African American Experience. Durham, NC: Duke University Press.

Loveland, Matthew T., David Sikkink, Daniel J. Myers, and Benjamin Radcliff. 2005. "Private Prayer and Civic Involvement." Journal for the Scientific Study of Religion 44(1):1-14.

Marti, Gerardo. 2012. Worship across the Racial Divide: Religious Music and the Multiracial Congregation. Oxford, UK; New York: Oxford University Press.

McAdam, Doug, John D. McCarthy, and Mayer N. Zald. 1996. Comparative Perspectives on Social Movements: Political Opportunities, Mobilizing Structures, and Cultural Framings. Cambridge, UK; New York: Cambridge University Press.

McAdam, Doug, Sidney G. Tarrow, and Charles Tilly. 2001. Dynamics of Contention. Cambridge, UK; New York: Cambridge University Press.

McCarthy, John D. and Mayer N. Zald. 1977. "Resource Mobilization and Social Movements: A Partial Theory." American Journal of Sociology 82(6):1212-41.

McCarthy, Thomas. 1995. "Legitimacy and Diversity: Dialectical Reflections on Analytical Distinctions." Cardozo Law Review 17:1083-125.

McPherson, Miller, Lynn Smith-Lovin, and James M. Cook. 2001. "Birds of a Feather: Homophily in Social Networks.” Annual Review of Sociology 27:415-44.

Menard, Scott. 2011. "Standards for Standardized Logistic Regression Coefficients." Social Forces 89(4):1409-28.

Morris, Aldon D. 1984. The Origins of the Civil Rights Movement: Black Communities Organizing for Change. New York: The Free Press.

Nepstad, Sharon Erickson. 2001. "Creating Transnational Solidarity: The Use of Narrative in the U.S.-Central America Peace Movement.” Mobilization 6(1):21-36.

Norris, Pippa and Ronald Inglehart. 2011. Sacred and Secular: Religion and Politics Worldwide. $2^{\text {nd }}$ Edition. Cambridge, UK; New York: Cambridge University Press.

Ortner, Sherry B. 1984. "Theory in Anthropology since the Sixties." Comparative Studies in Society and History 26(1):126-66. 
Osterman, Paul. 2003. Gathering Power: The Future of Progressive Politics in America. Boston: Beacon Press.

Ostrower, Francie. 2007. Nonprofit Governance in the United States: Findings on Performance and Accountability from the First National Representative Study. Washington, DC: The Urban Institute.

Parekh, Bhikhu C. 2002. Rethinking Multiculturalism: Cultural Diversity and Political Theory. Cambridge, MA: Harvard University Press.

Pattillo-McCoy, Mary. 1998. "Church Culture as a Strategy of Action in the Black Community." American Sociological Review 63(6):767-84.

Polletta, Francesca. 1999. “"Free Spaces' in Collective Action.” Theory and Society 28(1):1-38.

Polletta, Francesca and James M. Jasper. 2001. "Collective Identity and Social Movements." Annual Review of Sociology 27:283-305.

Pulido, Laura. 1996. "Multiracial Organizing among Environmental Justice Activists in Los Angeles." Pp. 171-89 in Rethinking Los Angeles, edited by M. J. Dear, H. E. Schockman, and G. Hise. Thousand Oaks, CA: Sage Publications.

Putnam, Robert D. 2007. "E Pluribus Unum: Diversity and Community in the Twenty-First Century.” Scandinavian Political Studies 30(2):137-74.

Putnam, Robert D. and David E. Campbell. 2010. American Grace: How Religion Divides and Unites Us. New York: Simon and Schuster.

Reger, Jo, Daniel J. Myers, and Rachel L. Einwohner. 2008. Identity Work in Social Movements. Minneapolis: University of Minnesota Press.

Sampson, Robert J., Doug McAdam, Heather MacIndoe, and Simón Weffer-Elizondo. 2005. "Civil Society Reconsidered: The Durable Nature and Community Structure of Collective Civic Action.” American Journal of Sociology 111(3):673-714.

Schwalbe, Michael L. and Douglas Mason-Schrock. 1996. "Identity Work as Group Process." Advances in Group Processes 13:113-47.

Sharp, Shane. 2012. "For a Social Psychology of Prayer.” Sociology Compass 6(7):570-80.

Skocpol, Theda. 2002. “United States: From Membership to Advocacy.” Pp. 103-136 in Democracies in Flux: The Evolution of Social Capital in Contemporary Society, edited by R. D. Putnam. New York: Oxford University Press.

Snow, David A. and Leon Anderson. 1987. "Identity Work among the Homeless: The Verbal 
Construction and Avowal of Personal Identities." American Journal of Sociology 92(6):1336-71.

Snow, David A. and Doug McAdam. 2000. "Identity Work Processes in the Context of Social Movements: Clarifying the Identity/Movement Nexus." Pp. 41-67 in Self, Identity, and Social Movements, edited by S. Stryker, T. J. Owens, and R. W. White. Minneapolis: University of Minnesota Press.

Stout, Jeffrey. 2010. Blessed Are the Organized: Grassroots Democracy in America. Princeton: Princeton University Press.

Stout, Linda. 1996. Bridging the Class Divide and Other Lessons for Grassroots Organizing. Boston: Beacon.

Swarts, Heidi J. 2008. Organizing Urban America: Secular and Faith-Based Progressive Movements. Minneapolis: University of Minnesota Press.

Tarrow, Sidney G. 1994. Power in Movement: Social Movements, Collective Action, and Politics. Cambridge, UK; New York: Cambridge University Press.

Tocqueville, Alexis de. 1969 [1835]. Democracy in America, edited by J. P. Mayer. New York: Harper \& Row.

Verba, Sidney, Kay Lehman Schlozman, and Henry E. Brady. 1995. Voice and Equality: Civic Voluntarism in American Politics. Cambridge, MA: Harvard University Press.

Warren, Mark R. 2001. Dry Bones Rattling: Community Building to Revitalize American Democracy. Princeton: Princeton University Press.

Whitman, Gordon. 2007. "Beyond Advocacy: The History and Vision of the PICO Network." Social Policy 37(2):50-59.

Williams, Katherine Y. and Charles A. O'Reilly. 1998. "Demography and Diversity in Organizations: A Review of 40 Years of Research." Research in Organizational Behavior 20:77-140.

Wood, Richard L. 1999. "Religious Culture and Political Action." Sociological Theory 17(3):307-332.

Wood, Richard L. 2002. Faith in Action: Religion, Race, and Democratic Organizing in America. Chicago: University of Chicago Press.

Wood, Richard L., Brad R. Fulton, and Kathryn Partridge. 2012. "Building Bridges, Building Power: Developments in Institution-Based Community Organizing." Boulder, CO: Interfaith Funders.

Wuthnow, Robert. 2002. "Religious Involvement and Status-Bridging Social Capital.” Journal 
for the Scientific Study of Religion 41(4):669-84.

Wuthnow, Robert. 2008. “Prayer, Cognition, and Culture.” Poetics 36(5-6):333-37.

Ruth Braunstein is Assistant Professor of Sociology at the University of Connecticut. Her research examines how citizens across the political spectrum struggle to assert their voices, values, and knowledge in public debates, and the complex role religion plays in this process. She is currently working on a book based on a comparative ethnographic study of faith-based community organizing and Tea Party activism.

Brad R. Fulton is a PhD candidate in sociology at Duke University. His research focuses on the causes and consequences of racial, socioeconomic, and religious diversity within organizations. Fulton was the lead researcher for the National Study of Faith-Based Community Organizing Coalitions, which has received awards from the American Sociological Association, the Academy of Management, and the Association for Research on Nonprofit Organizations and Voluntary Associations.

Richard L. Wood is Associate Professor of Sociology at the University of New Mexico. His research focuses on the cultural and institutional underpinnings of democracy. In 2003, Faith in Action: Religion, Race, and Democratic Organizing in America (University of Chicago Press 2002) was named outstanding book in the sociology of religion by the American Sociological Association. His co-authored book with Brad R. Fulton, A Shared Future: Enacting Ethical Democracy in a Multicultural Society, is currently under review. Wood is writing Faith and the Fire of Public Life, on the impact of democratic engagement on faith communities. He serves as co-editor of a book series, Cambridge Studies of Social Theory, Religion, and Politics.

Table 1. Descriptive Statistics for Interfaith and the Entire Field of Faith-Based Community Organizing Coalitions and Their Boards

\begin{tabular}{lrrrrr}
\hline Variable & $\begin{array}{c}\text { Interfai } \\
\text { th }\end{array}$ & Mean & SD & Min & Max \\
\hline Prayer Vigils & 1.00 & .60 & .49 & .00 & 1.00 \\
Characteristics of Coalitions & & & & & \\
$\quad$ Located in the South & .00 & .27 & .45 & .00 & 1.00 \\
$\quad$ Male director & .00 & .52 & .50 & .00 & 1.00 \\
$\quad$ Age of director & 45.00 & 45.21 & 12.82 & 25.00 & 78.00 \\
$\quad$ Religiosity of director & 20.00 & 15.21 & 3.46 & 4.00 & 21.00 \\
Religious Composition of Boards & & & & & \\
$\quad$ Proportion Catholic & .44 & .36 & .22 & .00 & 1.00 \\
$\quad$ Proportion Mainline Protestant & .30 & .29 & .20 & .00 & .78 \\
$\quad$ Proportion Black Protestant & .15 & .19 & .21 & .00 & 1.00 \\
$\quad$ Proportion Conservative Protestant & .00 & .07 & .09 & .00 & .41 \\
$\quad$ Proportion Jewish & .07 & .05 & .08 & .00 & .35 \\
$\quad$ Proportion Muslim & .04 & .01 & .03 & .00 & .13 \\
$\quad$ Proportion Other & .00 & .03 & .09 & .00 & .50 \\
$\quad$ Religious diversity of board & .69 & .59 & .16 & .00 & .79 \\
$\quad$ Proportion clergy & .22 & .30 & .21 & .00 & 1.00 \\
Racial Composition of Boards & & & & &
\end{tabular}


Proportion white

Proportion black

Proportion Hispanic

Proportion other

Racial diversity of board

Household Income Composition of Boards

Proportion that earns less than $\$ 25,000$

per year

Proportion that earns $\$ 25,000$ to $\$ 49,999$ per year

Proportion that earns $\$ 50,000$ to $\$ 74,999$

per year

Proportion that earns $\$ 75,000$ to $\$ 100,000$

per year

Proportion that earns more than $\$ 100,000$

per year

Income diversity of board

Educational Composition of Boards

Proportion with less than a bachelor's degree

Proportion with a bachelor's degree

Proportion with more than a bachelor's degree

Educational diversity of board

Challenges Bridging Racial Differences

Extent racial differences complicate meetings

Extent racial differences prolong meetings

Challenges Bridging Socioeconomic

Differences

Extent socioeconomic differences

complicate meetings

Extent socioeconomic differences prolong meetings

\begin{tabular}{|c|c|c|c|c|}
\hline .33 & .49 & .26 & .00 & 1.00 \\
\hline .59 & .29 & .25 & .00 & 1.00 \\
\hline .07 & .18 & .23 & .00 & 1.00 \\
\hline .00 & .04 & .08 & .00 & .58 \\
\hline .53 & .46 & .17 & .00 & .73 \\
\hline .15 & .23 & .18 & .00 & .75 \\
\hline .33 & .35 & .18 & .00 & 1.00 \\
\hline .41 & .25 & .17 & .00 & .90 \\
\hline .04 & .12 & .13 & .00 & .88 \\
\hline .07 & .05 & .10 & .00 & .70 \\
\hline 1.05 & .94 & .29 & .00 & 1.69 \\
\hline .11 & .25 & .19 & .00 & .80 \\
\hline .44 & .34 & .19 & .00 & .91 \\
\hline .44 & .41 & .20 & .00 & 1.00 \\
\hline .68 & .73 & .18 & .00 & 1.15 \\
\hline 1.00 & 2.06 & 1.12 & 1.00 & 5.00 \\
\hline 1.00 & 1.94 & 1.18 & 1.00 & 5.00 \\
\hline 1.00 & 1.91 & 1.06 & 1.00 & 5.00 \\
\hline 1.00 & 1.80 & 1.03 & 1.00 & 5.00 \\
\hline
\end{tabular}

Source: 2011 National Study of Faith-Based Community Organizing Coalitions $(N=144)$. (Fulton et al. 2011)

Table 2. Logistic Regression Models Estimating Whether a Coalition Has Prayer Vigils

\begin{tabular}{lccccc}
\hline & Model 1 & Model 2 & Model 3 & Model 4 & Model 5 \\
\hline & - & - & - & - & - \\
Located in the South & $.335^{* * *}$ & $.448^{* * *}$ & $.332^{* * *}$ & $.339^{* * *}$ & $.447 * * *$ \\
& $(-7.016)$ & $(-9.738)$ & $(-7.065)$ & $(-6.981)$ & $(-9.268)$ \\
Male director & -.052 & -.064 & -.063 & -.045 & -.042 \\
& $(-1.098)$ & $(-1.381)$ & $(-1.314)$ & $(-.957)$ & $(-.880)$ \\
Age of director & $-.106^{*}$ & $-.122^{* *}$ & $-.108^{*}$ & $-.126^{* *}$ & $-.143^{* *}$ \\
& $(-2.342)$ & $(-2.782)$ & $(-2.429)$ & $(-2.766)$ & $(-3.328)$ \\
Religiosity of director & $.300^{* * *}$ & $.289^{* * *}$ & $.265^{* * *}$ & $.284^{* * *}$ & $.245^{* * *}$ \\
& $(5.827)$ & $(5.885)$ & $(5.008)$ & $(5.514)$ & $(5.430)$ \\
Religious diversity of board & $.138^{* *}$ & .019 & $.145^{* *}$ & $.179^{* * *}$ & .066 \\
& $(2.890)$ & $(.300)$ & $(2.931)$ & $(3.660)$ & $(1.096)$ \\
At least one Muslim board & & & & & \\
member & $-.099^{*}$ & $-.111^{*}$ & -.065 & -.072 & -.076
\end{tabular}




\begin{tabular}{|c|c|c|c|c|c|}
\hline \multirow{3}{*}{$\begin{array}{l}\text { Proportion of board that is } \\
\text { clergy }\end{array}$} & $(-2.257)$ & $(-2.574)$ & $(-1.526)$ & $(-1.652)$ & $(-1.762)$ \\
\hline & & -051 & 103 & 099* & .021 \\
\hline & $\begin{array}{l}.034 \\
(.744)\end{array}$ & $(-1.060)$ & $(1.820)$ & $(2.032)$ & $(.407)$ \\
\hline Racial diversity of board & & $\begin{array}{c}.192 * * \\
(3.447)\end{array}$ & & & $\begin{array}{c}.141 * * \\
(2.664)\end{array}$ \\
\hline Proportion of board that is & & & & & \\
\hline black & & $\begin{array}{l}.352^{* * * *} \\
(6.175)\end{array}$ & & & $\begin{array}{l}.359 * * * \\
(6.445)\end{array}$ \\
\hline Income diversity of board & & & $\begin{array}{c}.131 * * \\
(2.806)\end{array}$ & & $\begin{array}{l}.156^{* * *} \\
(3.224)\end{array}$ \\
\hline $\begin{array}{l}\text { Proportion of board that earns } \\
\text { less than } \$ 50,000 \text { per year }\end{array}$ & & & $\begin{array}{l}.273 * * * \\
(5.364)\end{array}$ & & $\begin{array}{l}.221 * * * * \\
(4.452)\end{array}$ \\
\hline Educational diversity of board & & & & $\begin{array}{c}-.019 \\
(-.290)\end{array}$ & $\begin{array}{l}-.046 \\
(-.742)\end{array}$ \\
\hline $\begin{array}{l}\text { Proportion of board with less } \\
\text { than a bachelor's degree }\end{array}$ & & & & $\begin{array}{l}.253 * * * \\
(3.963)\end{array}$ & $\begin{array}{r}.133^{*} \\
(2.072)\end{array}$ \\
\hline Log Likelihood & -85.278 & -77.269 & -81.294 & -82.367 & -72.613 \\
\hline
\end{tabular}

Note: $N=144$. Coefficients are fully standardized; $z$-statistics in parentheses; constants are not displayed. $* p<.05 ; * * p<.01 ; * * * p<.001$ (two-tailed tests).

Table 3. Logistic Regression Models Estimating Whether a Coalition Has Prayer Vigils

\begin{tabular}{|c|c|c|c|c|}
\hline & Model 1 & Model 2 & Model 3 & Model 4 \\
\hline $\begin{array}{l}\text { Extent racial differences complicate } \\
\text { meetings }\end{array}$ & $\begin{array}{l}.152 * * \\
(2.787)\end{array}$ & & & \\
\hline $\begin{array}{l}\text { Extent racial differences prolong } \\
\text { meetings }\end{array}$ & & $\begin{array}{l}.188 * * * \\
(3.609)\end{array}$ & & \\
\hline $\begin{array}{l}\text { Extent socioeconomic differences } \\
\text { complicate mtgs. }\end{array}$ & & & $\begin{array}{l}.223 * * * \\
(4.325)\end{array}$ & \\
\hline $\begin{array}{l}\text { Extent socioeconomic differences } \\
\text { prolong mtgs. }\end{array}$ & & & & $\begin{array}{l}.171 * * * \\
(3.587)\end{array}$ \\
\hline Log likelihood & -71.514 & -70.815 & -69.773 & -70.790 \\
\hline
\end{tabular}

Note: $N=144$. Each model also contains all of the variables in Model 5 of Table 2. Coefficients are fully standardized; $z$-statistics in parentheses; coefficients of control variables and constants are not displayed. $* p<.05 ; * * p .01 ; * * * p<.001$ (two-tailed tests). 
Figure 1. Predicted Probabilities of a Coalition Having Prayer Vigils Conditioned on the Extent to Which It Faces Challenges Bridging Racial and Socioeconomic Differences

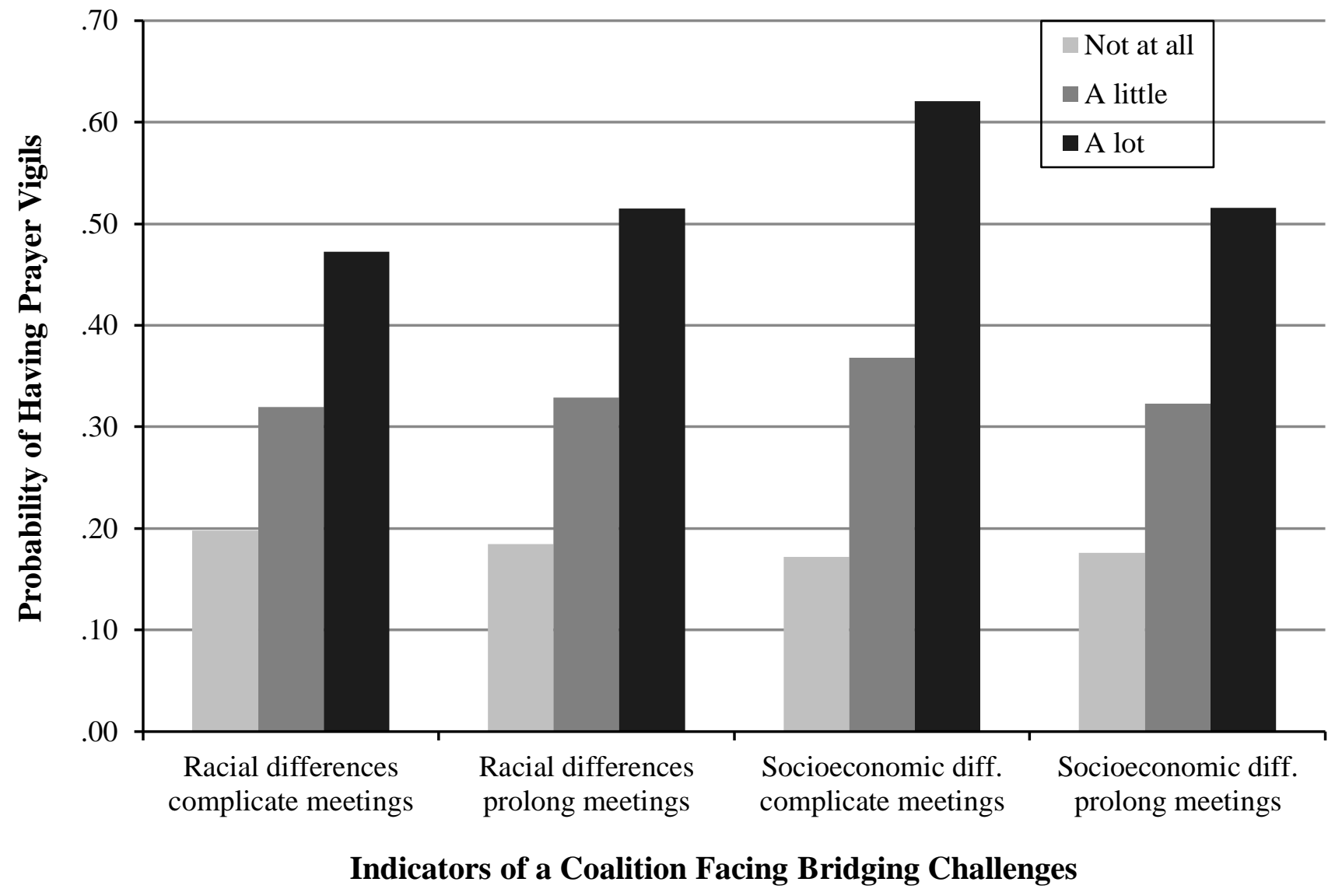

Note: Predicted probability calculations are based on a coalition located in the South, with a male director, and no Muslim board members; all other control variables are set to their mean values. 